\title{
Plagio electrónico: la otra cara del APA
}

\author{
Aníbal Alemán, Ramiro Castillo, Freddy Quezada, Hazel Rueda. \\ Somos minorías autoritarias frente a masas \\ sin conciencia, al parecer, de comisión de faltas.
}

Recepción: 21-02-2016 / Aceptación: 18-05-2016

\begin{abstract}
Resumen
El presente artículo trata sobre el tema del plagio electrónico. Dicho documento se estructura en tres partes. Al inicio se aborda el plagio desde el ámbito epistémico que tiene una relación, quizás no tan directa, con la verdad como adecuación, a través de un procedimiento científico que busca resultados, entre un sujeto y un objeto. Seguidamente se analiza desde el ámbito de la ética, donde circula en forma de penalizaciones y observancia de procedimientos, normas y deberes a guardar en la diferencia perfecta entre un original y un fraude. Posteriormente se analiza el aspecto estético donde encuentra su nudo y complejidades más fecundas, pues, es el terreno del original, como obra de arte, y su reproductibilidad mecánica, y hoy electrónica, que la despoja de toda singularidad y la abre al nuevo poder de participación de los usuarios, en el sentido de Walter Benjamín, reenviándola al campo epistémico. Por último, se presentan tres escenarios, con el propósito de luchar como creyentes en tierra de infieles; a negociar otras condiciones; o a rendirnos con honor y dignidad.
\end{abstract}

\section{Palabras claves}

Plagio, copia, pegar, fraude, copy and paste, original, emisor, receptor.

\begin{abstract}
This essay regards about electronic plagiarism. It consisted in three parts. At the beginning plagiarism is approached from epistemic scope that has not direct relation with truth as adequacy through a scientific procedure looking for results related to a subject and object. Secondly it is analysed since the ethic point of view that function as penalty, rules and duties respect to an original or fraud. Later it is analysed the aesthetic aspect where can be found its complexity. Also as with originals artworks, mechanical or electronically reproduction, stripped of all singularity and open it to the new power of users participation, as Walter Banjamin stressed, sending it back to epistemic field. Finally three scenarios are presented to counteract: conservative, negotiator and open or conservative, negotiator and open or ethical scenarios.
\end{abstract}

Key words: Plagiarism copy, fraud, copy and paste, original, transmitter, receiver.

\section{Presentación}

El objetivo fundamental de estas notas, elaboradas por un equipo de profesores de la carrera de "Comunicación para el desarrollo" de la UNAN- Managua, y contando con la edición del Msc Walter Calderón Ramírez, es sincerar el problema del plagio electrónico a través de la discusión académica, por medio de mesas, debates, foros, entre otros, además de proporcionar pistas para su agenda $\mathrm{y}$ escenarios para sus salidas.

El plagio es parte orgánica de la piratería, un mal universal que, junto al cambio climático, la inmigración, el narcotráfico, el terrorismo 
y las epidemias mundiales, pertenecen a ese rango de fenómenos que exigen el concurso de todas las naciones para mitigarlos y que hizo nacer la célebre definición de los estados nacionales contemporáneos como aquellos "demasiado grandes para resolver los pequeños problemas y demasiado pequeños, para resolver los grandes".

Estamos ante un asalto masivo y universal de plagios que son entregados como trabajos de cursos bajo la definición de investigaciones, ensayos, proyectos o diagnósticos. Situados en lo que a veces pareciera un callejón sin salida, una buena parte de los docentes de las universidades del mundo, sabemos que nos volvemos, por indolencia, pereza y vista gorda, en cómplices de un modo masivo de fraude conocido en inglés como "copy and paste", copiar y pegar. Debido a la facilidad, accesibilidad y masividad ${ }^{1}$ de la fuente de donde pueden ser tomados los originales, o los tenidos por tales, delante de una pantalla electrónica, se ha vuelto un problema su "otro": el plagio.

Y de ético, este fenómeno reclama, también, una valoración epistémica, que tenga que ver no sólo con las faltas a un régimen de deberes, de suyo sancionables, sino con la revisión entre original y copia, que se ha mantenido por siglos en nuestra cultura ${ }^{2}$ y que, sólo hasta que se le hizo intervenir al juicio estético, se han abierto nuevas posibilidades de examinar el asunto, desde perspectiva de usuarios, consumidores y receptores.

Decimos, pues, que hay tres campos en conflicto en este fenómeno: epistémico, ético y estético. Los clásicos campos kantianos.
En el primero, se trata de la verdad como correspondencia; en el segundo, de las penalizaciones sobre la violación de los originales y, en el tercero de la interpretación y ahora, facilitado por la accesibilidad de los archivos, la co-participación de los receptores en las obras. La vorstellung y la darstellung, ${ }^{3}$ en el primer y tercer caso y, de las infracciones, en el segundo. La verdad, el deber y el original.

Se trata de la representación y la reproducción como voluntad de un sujeto en los tres reinos, para el cual todo es un objeto que puede crear, estudiar, manipular, repetir, construir, rehacer, alterar o darse la libertad de opinar sobre él, con el mismo derecho que le asistiría a cualquier otro, si es una obra de arte.

Lo que parece suceder ahora es que la ética invade el campo de la estética y ésta, a su vez, relanza la episteme con la co-participación de los usuarios, convirtiendo todo en terreno del giro hacia los receptores, audiencias y usuarios. Y, en consecuencia, las amenazas hacia la autoridad del sujeto y el desafío hacia los emisores y sus códigos penales.

Hay, en síntesis, dos caminos ante la relación de originales y copias: o cerramos los ojos ante el fenómeno y nos hacemos cómplices de algunas de sus etapas o nos decidimos a revisar de raíz el fenómeno que cuenta con su presencia en, al menos, los tres ámbitos mencionados, que pueden ser distintos o no, será asunto de investigación, y los emplearemos como apartados para arriesgar algunas pistas y anunciar, al final, algunos escenarios.

1 Es una era donde Tántalo ha sido liberado y dispone en abundancia de todos los bienes simbólicos, privados durante un suplicio en que, cada vez que padecía sed no podía saciarla, por el retiro inmediato del río al que estaba encadenado, ni comer las jugosas uvas por encima de su cabeza, cada vez que deseaba morderlas, porque se le rehusaban. Es un cuerno de la abundancia que en su tumultuosidad e ímpetu puede que esté creando, si decidimos otorgarle el beneficio de la duda, al copiar, amalgamar y destruir.

2 Quizás el verdadero despegue de esta discusión sea preguntarse si las ideas pueden tener propietarios o no. Y si el APA no es más que un régimen de propietarios simbólicos, como los que se declararon dueños de una tierra que ya estaba antes de nosotros, anunciando la aparición de la propiedad privada como un robo, según las lecturas de Proudhon y Marx.

3 La Vorstellung nos (re) presenta las cosas dos veces: en su ausencia y como categoría mental; hacia dentro. La Darstellung, dos veces también, al original ausente y a un actor que lo recrea; hacia fuera. Aquél en la razón pura; éste en la estética. Ambas, hoy, objetos del "regreso de lo reprimido" que hizo abandonar su viejo fundamento de "olvidar diferencias", por el "otro", actual, de recordarlas. 
No conocemos una investigación a fondo, en las Universidades de Nicaragua, sobre el plagio académico. Una de las razones que nos animó a escribir estas notas es precisamente justificar la necesidad de contar con una línea de investigación declarada, al menos en la UNAN-Managua, para empezar a formular proyectos de investigación para el caso.
En ese sentido, como antecedente, a continuación presentamos algunos datos de una investigación de Donald McCabe, citada por Amador (2010), sobre su impacto a nivel académico, aplicando encuestas a estudiantes de pregrado y posgrado de distintas universidades de Estados Unidos a lo largo de 3 años.

\section{Plagio}

\begin{tabular}{||l|c|c|}
\hline \hline INFRACCIÓN & PREGRADO & POSGRADO \\
\hline \hline Parafrasear o copiar de una fuente escrita algunas oraciones sin referenciarlo & $36 \%$ & $35 \%$ \\
\hline \hline Parafrasear o copiar de Internet algunas oraciones sin referenciarlo & $32 \%$ & $31 \%$ \\
\hline \hline Fabricar o falsificar una bibliografía & $14 \%$ & $13 \%$ \\
\hline \hline Entregar un trabajo copiado de otra persona & $8 \%$ & $7 \%$ \\
\hline \hline Copiar casi palabra por palabra de una fuente escrita sin citarlo & $7 \%$ & $6 \%$ \\
\hline \hline Obtener un artículo de un sitio de Internet de venta de artículos & $3 \%$ & $8 \%$ \\
\hline \hline TOTAL & 100 & 100 \\
\hline
\end{tabular}

Fuente: McCabe, citado por Amador (2010)

Es evidente que un porcentaje considerable de estudiantes tanto en el nivel de pregrado y posgrado, admiten el haber parafraseado oraciones ya sea de Internet o de una fuente escrita, sin citar la fuente de origen. Esto representa un gran problema de plagio, ya que probablemente la mayoría de estos estudiantes creen que hacen bien al no poner la referencia cuando se parafrasea, situación que no es así, ya que de igual forma se está cometiendo plagio.

Algunas universidades han tomado cartas en el asunto, para tratar de evitar el problema del plagio. Un ejemplo es la Universidad de Costa Rica que considera la acción del plagio como una falta muy grave. Desde febrero del 2010, copiar de forma total o parcial una obra intelectual de cualquier tipo, o presentar como propio el trabajo realizado por otras personas es considerado como falta muy grave. Así quedó acordado por el Consejo
Universitario, el cual hizo la modificación respectiva al Reglamento de Orden y Disciplina de los Estudiantes (Amador, 2010).

Con esta medida se pretende resolver y desincentivar a los plagiadores a que cometan este tipo de actos fraudulentos que atentan contra la formación académica y profesional quela UCR brinda a sus estudiantes. (Amador, 2010). Esta modificación al reglamento se originó a partir de una solicitud hecha por el director de la Escuela de Filosofía, Dr. Manuel Triana. (Amador, 2010)

Las faltas muy graves como cometer plagio, se sancionan con la suspensión del estudiante por un plazo no menor de 6 meses calendario y hasta un máximo de 6 años calendario. Dependiendo de la situación del estudiante estas sanciones pueden ser sustituidas por medidas correctivas que varían según cada caso. 


\section{Ámbito epistémico}

La relación del original con la copia, tiene una relación, quizás no tan evidente, con la verdad como adecuación, a través de un procedimiento científico que calcula y busca resultados, entre un sujeto y un objeto. Si habláramos de una bisagra, diríamos que es la autenticidad en el sentido que le imprimió Heidegger, como verdad (aletheia) del Dasein y su originalidad para cada caso. Toda la actividad está del lado de unos expertos autorizados que, en el campo de la comunicación, llamamos emisor. Ellos cuentan con las llaves de algo de su perfecto dominio que no siempre presentan como fruto de combinaciones anteriores, y otros resultados, y que las hacen desembocar en un nuevo régimen de verdades. Casi podríamos decir que la verdad equivale a un original por medio de las esencias eternas que ambas declaran abrigar. Cuentan con el mismo registro y participan de muchos principios comunes.

En términos epistémicos sabemos que hay que revisar la relación que se ha guardado siempre para mantener un régimen aristotélico/kantiano, entre copia y original. Separación que funda a nuestras universidades, industrias y comercio de símbolos. Este sería el despegue teórico para el despeje del impasse. Toda reflexión del asunto se enmarcaría a partir de tal separación. Y se desdoblaría entre campo epistémico (la representación como adecuación entre un sujeto y un objeto que pasaría por verdad y original) y un régimen ético que sería su guardián y custodio.

Un original electrónico puede ser original, pero también una copia, o mezcla de copias, que impediría ser presentada como prueba de original, para penalizar una falta sin cuerpo de delito. La situación ha llevado a desconfiar de autorías en primera instancia que no cuentan con garantías de ser, a su vez, originales. Hay "memes", por ejemplo, que arbitraria y jocosamente atribuyen frases y aforismos a personas que no son sus autores, sembrando el escepticismo no sólo sobre los responsables directos del engaño, que no rinden cuentas a nadie y también nadie se las exige, sino en el medio que lo permite y desestabiliza todo. Uno estaría tentado de decir que el desorden y las combinaciones, prueban ser creativas en mano de los diseñadores gráficos que usualmente crean, entre otras cosas, a partir de réplicas, como los "memes", borrando las fronteras entre originales y creaciones a base de copias. Lo otro y, a la vez, lo mismo del plagio, son los diseñadores gráficos.

La copia de una copia, suspendería el castigo y nos llevaría a la cuestión de la huella originaria, como Derrida miraba las cosas, que nunca hallaremos, convirtiéndose todo en copia o recirculación de mezclas de mezclas y haciendo innecesaria toda ética y en consecuencia todo castigo. Sería como un regreso a los orígenes bajo el principio que nadie es dueño de las ideas, llamando autor sólo a aquél que las combina sobre hombros de sus antecesores.

Una situación así, nos autorizaría a pensar que Platón, por ejemplo, sólo hizo una mezcla, sin duda creadora, entre Parménides y Heráclito, para fundar la concepción que aún domina a toda la cultura occidental, de una ousía eterna y un flujo de lo real, lleno de incertidumbres y movilidades. Marx, también dentro de este escenario, sería juzgado como un combinador, genial sin duda, al unir la economía inglesa con las especulaciones filosóficas alemanas. Del mismo modo, Parsons que unirá a Max Weber con Emile Durkheim y Heidegger a Nicolás de Cusa con Meister Eckart. La pureza estaría bajo fuego y con ella la originalidad. Nada nace de la nada. Ex nihilo nihil fit. 


\section{Ámbito ético}

No obstante, el tema del plagio no es un asunto que ocupe, única y exclusivamente a los estudiantes a nivel de pregrado, aunque siempre es a ellos a quienes se les señala, también es un problema en niveles superiores, incluso hay profesores que han sido destituidos de su función docente por cometer el delito de plagio. Esto evidencia que no es un problema generacional, como algunos creen, esto solo demuestra que el plagio es un asunto de ética.

En la Universidad Nacional Autónoma de México (UNAM), específicamente en la Facultad de Filosofía y Letras, un profesor fue dado de baja de sus funciones por incurrir en "graves deficiencias en las labores docentes o de investigación, objetivamente comprobada". El copy and paste, como popularmente se le conoce, es una práctica que incluye a todos y todas, ante esta problemática las universidades están haciendo intentos severos por eliminarla de la comunidad académica e intelectual, sin embargo, no es una tarea fácil, pues están en juego los valores éticos y morales que se supone, deben ser fomentados e inculcados desde el seno familiar.

En este caso, es motivo de alarma el hecho que tanto estudiantes como autoridades académicas, están repitiendo patrones de conducta de sus mismos mentores, ante esto, la tarea se vuelve más compleja aún, pues para erradicar el plagio de las actividades intelectuales es preciso que sean los mismos docentes quienes se sensibilicen sobre el tema de honestidad y producción epistemológica, para que su preocupación pueda ser transmitida a los discentes.
La relación de original con la copia, es en este ámbito donde circula en forma de penalizaciones y observancia de procedimientos, normas y deberes a guardar en la diferencia perfecta entre un original y un fraude. Estos códigos, hasta donde vamos, han tratado de refinarse por las comunidades de jueces académicos, para salirle al paso a la generalización de las faltas, o atemperarlas, con un sistema de patentes autorales, parecido a un listado protegido de inventores, conocido como APA por sus siglas en inglés (Alemán y Quezada, 2015). Le llamaremos mensaje a esta dimensión, en virtud del diagrama de la comunicación. Recortar o endurecer estos códigos pertenece a la familia de proposiciones a considerar, según la salida que se recomiende para lo que, desde este ámbito, constituye un escándalo. Lo veremos al final.

Hablaremos exclusivamente aquí del plagio y la actitud ética ante él. Hay conceptos vecinos con los que a veces se confunde y en efecto guarda fuertes coincidencias. Umberto Eco profundiza, a veces se complica $y$, de paso, nos arrastra con él, en las diferencias entre copia, falsificación, facsímil, apócrifo, pastiche, doble, piratería, imitación, plagio artístico, reproducción y otros (Eco, 1992: 181-208). ${ }^{4}$ El plagio, objeto de nuestra investigación, lo definiremos, para no intoxicarnos con la embriaguez diferencial de Umberto Eco, strictu sensu, en su sentido más estrecho, como citar íntegro algo ajeno, de preferencia escrito, y ocultar la fuente.

Los profesores recibimos ensayos e investigaciones sin referencias ni citas que abren un juego persecutorio entre profesores y estudiantes, como el que observamos en esas series de televisión entre policías y ladrones. Muchos de nosotros, a veces,

4 Umberto Eco, como seguidor de Aristóteles, es el profesional de nuestra era para subdividir una categoría, y definirlas, hasta el paroxismo. Si fuera consecuente hasta el final, Eco tendría que incluir, dentro de las variedades, al opuesto, al original, redondear todo y, al dejarse arrastrar por lo creado, donde el observador también sería cubierto por el espectro, desaparecer detrás de una nubecilla de humo como la que emplean los magos para impresionar a los niños. No se puede subdividir una categoría hasta el infinito porque, como Funes el memorioso, no nos alcanzaría tiempo para pensar. Un cardumen de diferencias sólo puede hacernos correr el riesgo de paralizarnos por medio de la anulación de unas por otras. No dejaba de asistirle razón al Borges del Funes el memorioso, cuando decía que "pensar es olvidar diferencias". 
dejamos creer que se nos engaña ya sea por cansancio, desidia, prisa, indolencia, renuncia y abandono.

El copy and paste, como es conocida la generación bajo estudio, de la que no están excluidos los propios jueces cuando ellos mismos son estudiantes de niveles superiores en maestrías y doctorados, es la versión académica de la piratería electrónica perseguible de oficio y ya debidamente penalizada en la legislación de muchos países. El equivalente entre la comunidad académica, para mitigar los daños, sería la generalización del empleo del régimen citacional conocido, por sus siglas en inglés, como APA. ${ }^{5}$ El recurso cómico, por lo demás, no dejaría de parecer la defensa de unos académicos exigentes, ante un enjambre enfurecido de abejas africanas, intentando detenerlas con una bibliografía en orden alfabético, como cuando se intenta azotar a una nube de moscas con un periódico doblado sobre sí mismo, en forma de barra, al mismo tiempo que salvar su trasero de las picaduras.

Hay dos cosas detrás del combate entre el APA y el plagio: el sentido de ahorro de trabajo de las nuevas tecnologías (la comodidad) y el concepto de un original de esencias eternas. El APA (como registro de propiedad y catastro de bienes intangibles) del lado de los profesores y el plagio aparentemente del lado de los estudiantes, sería algo así como la batalla campal desencadenada en las comunidades de estudio del planeta entero.

Para los plagiadores, como para el pirata, sin embargo, parece no haber conciencia del delito. Este lo justifica con su situación económica; aquellos, con la abundancia, tentación y facilidad de los registros $\mathrm{y}$ bancos de información que suelen fundir información con educación, cubierto todo bajo un radar ameno de entretenimiento.
Hay una relación diferente entre ellos y los archivos electrónicos; diferentes a los de la generación de la imprenta. $Y$ en ese cambio o diferencia posiblemente radiquen algunas explicaciones al misterio y "abuso" que, acaso, tenga que ver con el sentido de toda tecnología de proporcionarnos confort y emplear el menor esfuerzo, la más baja cantidad de energía física y la mayor velocidad en las operaciones. Debe haber un punto en la curva, digna de investigación, donde se operó el "giro" entre estudiantes y profesores y el terreno ético fue abandonado a favor de una relación epistémica, reenviada por la permisividad estética, desde la capacidad de los usuarios de manipular contenidos.

Todo pasó de la moral única a los derechos de los usuarios; de los originales a la accesibilidad; de la autenticidad a las combinaciones; de la pureza de una verdad al derecho de miles de ella; de la autoridad de los pocos a la libertad de los muchos; de la episteme a la doxa. La diferencia ahora es la velocidad de los plagios y la cantidad de los plagiadores. El poder del número rompió los candados de operaciones regulables con códigos severos y su dominio anunciaprobablemente otro régimen de valores. Un músico, Peter Wolf, decía, reconociendo la gratuidad, anonimato $\mathrm{y}$ patrimonio colectivo de toda idea, uniéndola sorprendentemente a la importancia de los receptores que "al final una idea no es tuya; es sólo tu interpretación sobre algo".

Para averiguar quién copia y no cita, es necesario usar el mismo recurso que sirve para el plagio: los archivos electrónicos. Es sencillo. Se toma al azar un fragmento de lo entregado, se copia, se coloca en la caja de Google y el motor de búsqueda nos lleva exactamente al sitio de donde fue tomado. Todo estudiante sabe que ese es el riesgo que corre y si se le sorprende en falta, penalizado.

5 Ver trabajo de Alemán y Quezada (2014) Consideraciones críticas sobre el sistema de referencias bibliográficas conocido por sus siglas en inglés como APA. 
Incluso ya existen programas electrónicos destinados específicamente para descubrir los plagios más inteligentes. Pero se usan muy poco. Se prefiere directamente Google.

Lo que debiera castigarse, y se deja pasar, por su número, es que no citen. No que parafraseen. Estos son recursos académicos autorizados por el uso y conocimiento de las reglas citacionales. Y muy probablemente, la paráfrasis haya sido la grieta que hizo crujir todo el edificio porque "copiandoy pegando", se pueden efectuar ajustes gramaticales, usualmente nexos adversativos y pequeños enlaces de sentido, para hacer pasar como paráfrasis, legalmente reconocida, una construcción ajena.

Ya cuando se le agregan opiniones propias, por muy pequeñas que sean $y$, si son sustantivas o no, será a discreción de un evaluador autorizado bajo nuevas reglas, deberá tomarse como creación. Benjamin decía que la cinematografía era creadora de Frankensteins, pero mantuvo más su atención en el monstruo que en el procedimiento de su creación. Monstruos o no, la creación hoy procede de combinaciones que perfectamente pueden ser de copiados y pegados de un modo desigual y combinado, para agregarle un atributo concebido como ley, por León Trotsky. Ya hay paradigmas que explícitamente emplean ese registro como espina dorsal de sus operaciones teóricas, sobre todo en las que alguna vez fueron colonias europeas, desde las escuelas que abordan la hibridez, como Gloria Anzaldúa, "chicana" del pensamiento de fronteras; Dipesh Chakravarty de la escuela de los subalternistas de la India; Homi Bhabha de la postcolonial y Néstor García Canclini de la teoría activa del receptor latinoamericano. Se extraña en los decoloniales que no hayan seguido explorando esta ruta $y$, antes bien, volvieran grupas a la vieja filosofía de la sospecha y a la castidad epistémica de sus actores privilegiados.

La falta y el delito son plaga y legión, desde el punto de vista de un juez severo, autoritario y exigente que podría activar alertas tempranas por la inversión de la escala de valores donde -- como solía decir cínicamente Picasso -- "el bueno imita; pero el mejor, roba". Mientras antes el número era controlable con las reglas y las penalizaciones, ahora ya no. O sí, pero es desgastante sancionarlo y la cantidad de plagiadores es tanta que sepultaría cualquier iniciativa, terminando los jueces por la salida más cómoda, fácil y dispensable: hacerse de la vista gorda.

La misma comodidad disponible para los "villanos", por las nuevas tecnologías que, en el fondo, lo que persiguen es el confort (a contrapelo de lo que pensaba Marx con ellas dentro del capitalismo ${ }^{6} \mathrm{y}$, a favor de lo que imaginó su yerno Paul Lafargue como derecho a la pereza, aún sin ellas), es la que usan, como justificación, los jueces para absolver a los pillos, al no servirse de ellas, bajo el principio jurídico de preferir liberar a un solo culpable, que condenar a miles de inocentes.

La pereza que facilita la tecnología, plagiar en el estudiante, es la misma del docente que también quiere gozarla, al no verificarlo.

El Heidegger tardío, al abandonar a sí misma a la metafísica (que iba, según él, de la filosofía hasta la técnica, pasando por la ciencia), se rindió ante la pereza que produciría la tecnología (una suerte de "dolce far niente") y un vacío angustioso ("horror vacui") llenado hoy con los mismos archivos electrónicos que lo ocasionan. Fruto de esa renuncia es su expresión que "sólo estando más cerca del peligro es que podremos salvarnos". Viejo recurso soteriológico venido del

6 Donde Hegel, Husserl y Heidegger creyeron ver en la tecnología, escisión, sentido y cálculo, lo que se mira es una búsqueda de pereza, al parecer a la velocidad de la luz por techo, hasta coronarse, para hacer efectiva cualquier orden, como una nueva utopía, con un control remoto universal, en vez del cetro imperial, en las manos de cada uno. 
principio oriental que "estamos más cerca del amanecer, sólo cuando estamos en medio de lo más oscuro de la noche". O, la que emplea Marx para justificar las esperanzas prometeicas en el proletariado, al decir que estos "no deberían tener absolutamente nada para, algún día, tenerlo todo".

\section{¿Antes no era así? ¿O lo era y retrospectivamente hasta ahora lo vemos?}

El surgimiento de la imprenta, a finales de la Edad Media, transformó la sociedad y abrió una nueva era al conservar el pensamiento escrito o la imagen $y$ difundirlos en numerosos ejemplares que luego llegaban a distintos receptores. Por este fenómeno de masificación, nacieron los derechos de autor, para evitar el hurto de libros y así proteger al mismo.

En la actualidad se habla más de plagio; sin embargo, siempre ha existido desde la invención de la imprenta. Cuando no existía la tecnología electrónica, las tareas e investigaciones se hacían a través de los libros, donde los estudiantes iban a las bibliotecas a realizar sus trabajos todo un día o una tarde. Posteriormente entregaban sus trabajos, pero el hecho de pasar varias horas sentados en una biblioteca con un libro, no levantaba sospechas que existía plagio; más bien, se reconocía el esfuerzo de los estudiantes. Este reconocimiento surge a partir de lo que los alumnos interpretaban de las lecturas que hacían, pero no se puede deducir que todo era interpretación, puesto que al momento de investigar, lo que se hacía era transcribir del libro al cuaderno y, así, presentarlo como trabajo propio.

El reconocimiento otorgado al estudiante en la era del libro, ya no será el mismo en la era de la tecnología, porque el fenómeno de "copiar y pegar" desde cualquier buscador de Internet, hace sospechar a cualquier docente, que los trabajos que calificamos son plagios $\mathrm{y}$, por ende, tienen que ser penalizados. A raíz de este fenómeno, podemos hacer una clasificación de dos tipos de plagios:

Plagio total: a veces castigamos fuerte cuando es demasiado el descaro, porque en muchas ocasiones los plagiarios sólo le cambian el nombre a los trabajos que encuentran en Internet y los presentan como propios.

Plagio parcial: es cuando el estudiante descarga varios trabajos de la nube y toma fragmentos de cada uno, armando una interpretación, presentándose como un trabajo original, muchas veces poco claro en las fuentes bibliográficas. A veces los docentes, vacilamos sobre cómo juzgar lo mal citado y algunas reflexiones propias, como valor agregado, dignas de ser consideradas. Los anclajes se vuelven formas estrictas de citar y el APA sirve de instrumento y látigo a la vez. Uno hasta podría imaginar que el APA nació como reaseguro de emisores perjudicados ante el copy and paste. Reacción de autores de siglo $X X$, ante plagiarios del XXI.

\section{Ámbito estético}

La relación de original con la copia, es aquí donde encuentra su nudo y complejidades más fecundas, pues, es el terreno del original, como obra de arte, y su reproductibilidad mecánica, y hoy electrónica, que la despoja de toda singularidad y la abre al nuevo poder de participación de los usuarios, en el sentido de Walter Benjamín, reenviándola al campo epistémico, pero como base para la discusión sobre la naturaleza de lo original y la creación a base de combinaciones. En términos de la comunicación, es el reino de los receptores.

La originalidad tiene su cuna en el arte. Aristóteles es el que la clasifica como mímesis creadora, como imitación de la naturaleza, pero con el valor agregado del autor. El dominio de tal principio, lo vino a romper Giambattista Vico, en el Renacimiento, por 
medio del giro que se opera con el tiempo lineal que funda el judeocristianismo y anuncia lo nuevo como lo original. La carga pasa de un pasado clásico a un futuro creador y sólo será Heidegger, con la autenticidad del ser, como elección propia de todas las posibilidades que el Dasein tiene, quien se detendrá en el presente.

El arte que despertará en los espectadores el gusto, en los términos presentados por Kant, es quien anunciará la entrada de la doxa, de la gente común y corriente, por arriba, aún custodiada por los críticos, y permitirá las opiniones más variadas que, convertidas después en textos, sonidos e imágenes, inaugurarán las escuelas hermenéuticas a partir de Gadamer y que terminarán por producir las teorías finitas del receptor de Eco y la diseminación de significados de Derrida.

Pero es Walter Benjamin el que anclará su mirada en las tecnologías reproductivas y las articulará con el aura del original y el carácter secular y desacralizado de las copias, indistinguibles de su referencia, como un primus inter pares, ${ }^{7}$ ya con el poder de permitir a grandes cantidades de usuarios componer contenidos sobre la base de los archivos. Muy parecido a lo que han hecho siempre los propios emisores clásicos de un modo oculto ${ }^{8}$ y lo que ya abiertamente declaran los autores de la hibridez, o pensamiento de fronteras, como se le conoce también.

La era de los receptores, pues, nos estaría regresando, en una especie de círculo, sin saber si será vicioso o no, al inicio epistémico. Vemos, pues, cómo se pasa del centro de atención del emisor, luego al mensaje, para terminar en la teoría del receptor, que lo permitió el juicio del gusto frente a las obras de arte y que, vuelta luego texto, permitirá la hermenéutica de las interpretaciones, la diseminación de los significados y el poder de los receptores, ya frente a archivos gigantescos, versátiles, dúctiles, elásticos y flexibles ${ }^{9}$ que serán fácilmente manipulables en sus contenidos, como una suerte de "zuhandenheit" heidegggeriana,lo que está a la mano y lo disponible cotidianamente a los entes.

\section{Resumamos, para estar claros.}

El arte reproducido, según Benjamin, es mera copia de un original que siempre está ausente. Pero así funcionan, también, los conceptos como exadaequatio de la verdad. La diferencia quizás sea que, en la episteme, gobierna el emisor $\mathrm{y}$, en la estética, los receptores, manteniéndose, diríamos que en medio, el respeto ético a reglas de un régimen donde ya se han consagrado los derechos de autenticidad y originalidad de los autores, que hoy se defienden bajo el escudo del APA. El problema está dividido de modo desigual $\mathrm{y}$, hoy podríamos decir que transversales, en los tres reinos que hizo célebre la obra de Kant y que deben mantener entre sí un equilibrio inalámbrico: la razón pura (teoría), la razón práctica (moral) y el juicio estético (arte). Verdad, bondad y belleza.

7 Los originales, como objetos, pasarán a ser resguardados y custodiados en los museos y colecciones públicas o privadas para establecer diferencias que jerarquicen las series a favor del teniente o de los emisores. Así, el metro original en un museo de París, las pinturas y manuscritos originales en bóvedas de bancos, en manos de coleccionistas privados y en bibliotecas públicas, no tendrán más valor, como demostrarán después los pragmáticos, que el de haber sido el primero o el más exacto. A partir del segundo, no habrán diferencias entre unos y otros, como las copias de ejemplares en los tirajes de los libros. Derrida le llamará a eso la huella originaria, la Ousía para Platón, que nos empeñamos en buscar y que en realidad no existe.

8 Es célebre la expresión de Newton cuando dijo que reducía sus méritos a definirse como un "enano a hombros de gigantes". La expresión, en la realidad, nos tienta creer que más bien pareciera conducirse al revés, como nos recuerda ese episodio de Mad Max donde el héroe descubre, al retirarle la máscara a su derrotado e imponente rival Master-Blaster, que no es más que un gigante con síndrome Downs, dirigido por un enano calculador.

9 Esta perspectiva de los archivos es diferente a la de Boris Groys, quien al situarse del lado del emisor, cree que son los museos de obras de arte los que deciden qué es lo nuevo, lo que no debe repetirse, algo que se puede decir hoy, también, de Google. Pero del lado de los receptores, el poder con el que hoy cuentan de participar directamente en la composición de los mensajes, hace que sea la combinación, y no la novedad, el "nuevo" principio. 


\section{Escenarios}

Si la montaña no viene a nosotros, tendremos que ir nosotros a ella. A luchar como creyentes en tierra de infieles; a negociar otras condiciones; o a rendirnos con honor y dignidad. El problema es tan grande, masivo y universal que amenaza con cubrir y tragar todas las salidas, al grado que el problema puede volverse, ya en la desesperación, convirtiendo la falta en virtud, en la solución misma.

Escenario conservador: Endurecer más las reglas y redoblar la carga para los jueces. Este escenario consistiría en aplicar, a todos los plagiarios que entreguen ensayos e investigaciones, marcos teóricos, historia y antecedentes en sus protocolos, el programa electrónico para detectar plagios. Significa recapacitar a todo el plantel docente y anunciarle a los plagiadores las nuevas reglas donde el plagio se sancionará severamente. También los propios docentes se someterán a tales reglas, pues, al ofrecer sus ensayos y sus tesis de postgrados, aceptarán ser sometidos a los programas detectores. El esfuerzo deberá consistir en usar pruebas aleatorias y representativas de todos los trabajos bajo su cargo y someterlos al detector. La recapacitación debe cubrir también asignaturas de refrescamientos clásicos que van desde Aristóteles con la mímesis hasta Kant con el concepto de representación, pasando por el punto de inflexión que anuncia Walter Benjamín, y que será el punto de partida de la hermenéutica gadameriana, la diseminación derridiana y todas las variedades post y decoloniales en sus ars combinatoria.

Escenario negociador: Flexibilizar las reglas a partir de examinar lo que no es repetición y reconocer lo creado a base de mezclas como digno de ser valorado. Es un escenario casuístico, despejable a partir de desconocer todo lo copiado y pegado y dictaminar los valores agregados, aún aquellos al amparo de paráfrasis.
Escenario abierto: En el fondo se trata del poder del número, del lugar de las verdades y de los originales en ese terreno. Hemos llegado a un punto, héroes y villanos, que debemos preguntarnos si los docentes no son minorías autoritarias frente a masas sin conciencia, al parecer, de la comisión de sus faltas. De eso se trata a lo que deseamos abrirnos. Renunciar a valorar regímenes citacionales y crear regímenes éticos por donde pasen las nuevas normas. ¿Cuáles? Lo dejamos abierto, como conjunto vacío, a la espera de ser el generador de nuevas mezclas.

\section{Conclusiones}

Sea lo que sea, lo cierto es que no pueden retrasarse las soluciones. La indolencia y permisividad, sólo acelerarán escenarios más radicales que amenazan con una revolución que hará saltar por los aires, todo el régimen académico como hasta hoy lo conocemos.

Cualquier solución que resolvamos tomar, debemos hacerla pasar antes por sincerar algo que ha sufrido la banalización de un mal que, de excepción ha pasado a ser regla $\mathrm{y}$, en consecuencia, exige cambios no sólo de juegos de lenguajes, sino de gramáticas, para un problema que pareciera una broma de meme estudiantil:

"Cuando le robas la idea a una persona, es plagio; pero, cuando es a muchas, es investigación".

\section{Referencias bibliográficas}

Alemán, A. Quezada, F. (2014) Consideraciones críticas sobre el sistema de referencias bibliográficas conocido por sus siglas en inglés como APA. Revista Humanismo y cambio social número 4.

Amador, A. (2010) Incluyen plagio como falta muy grave en la UCR. Boletín electrónico Enlaces, 38. Recuperado 
el 27 de mayo del 2016, de http:// boletin.cu.ucr.ac.cr/notas/38-2010/ plen06-3810.html

Benjamín, W. (1989).La obra de arte en la época de su reproductibilidad técnica. Taurus: Buenos Aires.

Eco, U. (1992). Límites de la interpretación. Lumen: México.

Soto, A (2012).El plagio y su impacto académico y profesional. Recuperada el 26 de mayo del 2016, de http:/ / ebci. ucr.ac.cr 